\title{
ALGUNS NEOLOGISMOS E PEREGRINISMOS DO PORTUGUES DO BRASIL
}

ZDENEK HAMPEJS

Nos nossos artigos "Para o estudo da linguagem da imprensa brasileira contemporânea" e "Mais algumas notas sôbre a linguagem da imprensa brasileira contemporânea", publicados na Revista Brasileira de Filologia, vols. I e II do tômo 6, respectivamente, registramos uma série de neologismos e peregrinismos que ainda não foram consignados, nem na $10 .^{a}$ ed. do Pequeno Dicionário Brasileiro da Lingua Portuguêsa (1960). Tôdas essas expressões foram recolhidas nas pesquisas que realizamos sôbre a linguagem dos jornais brasileiros atuais.

Depois de têrmos entregue os dois manuscritos à redação da $R B F$, encontramos ainda alguns têrmos que consideramos dignos de registro. Como a devida abonação que acompanha cada um dos têrmos mostra, foram colhidos nos jornais cariocas e recifenses dos primeiros meses do ano de 1961. Já advertimos nos dois citados estudos, que não pretendemos superestimar o valor dessas expressões que às vêzes não passam de meros peregrinismos de curta vida, de invenções dos jornalistas, etc.; mas inclusive êstes têrmos podem contribuir para o estudo das tendências criadoras da língua. Os outros têrmos - os "não-peregrinismos" - constituem as nossas modestas achegas para os dicionários da língua.

As palavras vêm sendo classificadas alfabèticamente, com a indicação da categoria e, nos substantivos, também do gênero, com a definição e a respectiva abonação.

AFRICANIZAÇão s.f. - ato de africanizar, isto é, dar feição africana, imprimir características próprias da Africa, ou de despertar um grande interêsse por êste continente: "Esta semana, a diplomacia brasileira deu um firme passo para a "africanização", com a aprovação pelo presidente da República do relatório do grupo de trabalho sôbre a África". Correio 
da Manhã, 9-4-1961; africanização não é palavra nova, mas não consta, p. ex., do $P D B L P$, ao contrário de africanizar.

AGARRA-AGARRA S.m. - briga, conflito: "A polícia estêve atenta aos mínimos detalhes de todos os bailes carnavalescos. Bastava surgir um agarra-agarra de conseqüências graves, para que imediatamente surgissem quatro ou cinco, às vêzes mais, policiais para acalmarem os ânimos". Dizem por ai, n. ${ }^{\circ}$; palavra esporádica e sem muita vida.

ALUNAGEM S.f. - ato de alunar, isto é, baixar a aeronave na lua: Manchete, n. ${ }^{\circ} 471$; a palavra não é recente, aparece, pelo menos, a partir de 1958; também se encontra: alunissagem s. f.

AMEAÇADA s.f. - ameaça; palavra expressiva formada com o sufixo muito comum em -ada: "Pelas declarações das duas mulheres, Roselito desfruta de um prestígio fabuloso, junto a alguns policiais. Porque, é com ameaçadas de prisões que êle consegue reter no Night and Day as mulheres que se rebelam e ameaçam abandoná-1o". Diário de Notícias, 8-4-1961.

aNtigalã s.m.: "Jean Paul Bellmondo inaugurou a era do "antigalã" ou do galã feio", Mundo Ilustrado, n.o 175 .

ASTRONAVE S.f. - aparelho para vôos cósmicos; palavra formada por analogia à "aeronave"; vj. intersideral.

AUTARQUIZAÇÃo s.f. - ato de imprimir a uma instituição ou a uma emprêsa caráter de autarquia: "Antigamente se falava de "autarquizaçāo". Hoje se fala de "emancipação e independência econômica". Roberto Oliveira Campos no Correio da Manhã, 26-2-1961.

AUTODETERMINAR v. - criar condições para a autodeterminação; inovação usada por Austregésilo de Athayde no Diárto da Noite, 25-4-1961: "Quem autodetermina Cuba?"

aUtofinanciável adj. - capaz de financiar-se a si mesmo: ". . Brasília não sòmente era autofinanciável como era fonte de bons lucros para a União", Oswaldo Costa no Semanário, 17-24-3-1961.

BATANÊS s.m. - expressão jocosa que alude ao fato de os baianos gostarem de proferir discursos com palavreado 
erudito; p.ex., num tópico que informa sôbre a reunião do Banco Interamericano, se diz: "Em meio ao discurso, todos êles mal acompanhavam a eloqüência baiana do orador. Um jornalista comentou: Esqueceram de contratar um tradutor de baianês". Correio da Manhã, 13-4-1961.

Banaúsque s.m. - "Quem gosta de uísque com água, deverá pedir um banauísque à base de banana d'água", Correio da Manhã, 22-4-1961.

BATINAUTo s.m. - navegador de batiscafo (=navio para as profundidades, construído por A. Piccard): "Que viram os "batinautos" na escuridão eterna dos abismos marinhos", Diversões Escolares, a. II, N.० 8.

BIOBAJULAR v. - verbo pilhérico que significa: bajular em forma de biografia: "O caso do deputado mineiro não é tão grave assim, pois, como diz um seu companheiro de bancada, "êle não resistirá por muito tempo à sua mania de biografar quem está lá por cima, na sua ânsia de conseguir o prêmio Nobel do puxa-saquismo". Tudo indica que, antes de emplacar 62, o atual líder do PSD biobajulará JQ." Correio da Manhã, 9-4-1961.

BôCA RICA S.m. - aproveitador de boas situações: "somos o país do futuro" - como diziam os bôca rica no tempo da ditadura", Diário da Noite, 20-3-1961.

BOLACHEAMENTo s.m. - ato e efeito de dar bolachas: "campo de bolacheamento puro e simples", Stanislaw Ponte Prêta, Diário da Noite, 18-2-1961; criação pessoal do jornalista.

BRIGITIANo adj. - referente ou semelhante a Brigitte Bardot: "A italianinha Cristina Cajoni é uma novata do tipo brigitiano...", Correio da Manhã, 11-3-1961; do nome da mesma atriz foram derivadas duas outras palavras registradas em "Para o estudo da linguagem da imprensa brasileira contemporânea" (6.4): bardolatria e brigitte. Tôdas essas expressões são efêmeras, como, na maioria dos casos, acontece com os têrmos derivados dos nomes dos atores, esportistas, políticos, etc.

CALAMITADo s.m. - aquêle que sofre as conseqüências de 
uma calamidade; p. ex.: "No mais, a calamidade, o calamitoso... e nós, os calamitados". Última Hora, 10-3-1961.

CANARINHo s.f. - recepcionista loura: "Amanhã as "canarinhos" dirão adeus". Última Hora, 17-3-1961.

CARIOCADA s.f. - grupo de cariocas: "A cariocada que enfrentou de peito aberto a maratona turfística paulista tirou o pé da lama no último páreo da última reunião, segunda-feira...", Correio da Manhã, 7-5-1961; a palavra lembra baianada e, noutro contexto, pode significar, também: atitude de carioca.

CARNAVÁLIA S.f. - assuntos referentes ao carnaval; palavra usada por Marques Rebêlo na Última Hora, 18-2-1961; formação pilhérica que lembra as palavras latinas em -ália.

CEPALISTA adj. - referente a CEPAL: "grupo chamado cepalista", Visão, 10-3-1961.

CHARGISTA S.m. - caricaturista; palavra muito rara derivada de "charge" (=caricatura): "O pintor Augusto Rodrigues vai voltar à imprensa carioca como "chargista" político", Correio da Manhä, 23-4-1961.

Co-FUNDADOR s.m. - um dos fundadores, aquêle que fundou alguma coisa em sociedade com outrem: "No Uruguai, foi co-fundador do SODRE. ..", Visão, 10-3-1961.

CoLcoze s.m. - fazenda coletiva (na URSS): "Após desmentir, com humor, os boatos de que seria descendente dos príncipes Gagarin e de que teria parentes na América Latina, afirmou o cosmonauta: "Sou filho de camponeses e nasci em um "colcoze"." Jornal do Commercio, 6-4-1961; a palavra foi registrada, com esta mesma ortografia, por A. G. Cunha nas "Influências eslávicas na lingua portuguêsa";

COMPLEXado adj. - que tem complexos: "A polícia admite que Antônio Amaral, talvez complexado pelo defeito físico, temia perder o amor de Katia, levando-a para a morte". Diário da Noite, 15-4-1961.

CONCLAPISTA S.m. - membro ou defensor do CONCLAP: "Gostei do tom em que Jânio replicou aos conclapistas". Ultima Hora, 16-3-1961. 
cosmonauta S.m. - navegador cósmico; pessoa que sobe ao espaço cósmico; assim foi denominado I. Gagárin depois do seu vôo; p. ex. Carlos Drummond de Andrade diz na sua crônica "Cosmonauta", Correio da Manhã, 14-4-1961: "Mas antes de estender minha curiosidade ao cosmos, sou um pequenino noticiarista da terra, da cidade, da minha rua, e diante do primeiro cosmonauta penso em muitos de meus semelhantes que neste momento fazem a longa viagem de ônibus, de um a outro bairro do Rio, gastando tempo superior ao de que êle precisou para libertar-se da lei da gravidade e confortàvelmente dar volta ao globo, mandando bilhetinhos como se estivesse sentado num gabinete em Brasília". A palavra apareceu já no dia 13 de abril, comentando o vôo de Gagárin do dia anterior; p. ex.: "A primeira frase do cosmonauta foi:- Contemplo a Terra". Correio da Manhã;

DESACUMULAÇÃo s.f. - ato e efeito de desacumular: "o horário -Jânio para o funcionalismo visava, em última análise, a provocar demissões em massa, desacumulações e a desestimular a corrida para o empreguismo", Oswaldo Costa, Semanário, 17-3-1961.

DESAFORISMO S.m. - Mário da Silva Brito denominou "Desaforismos" o seu livro, publicado pela Ed. Civilização, 1961; no Correio da Manhã, 9-5-1961, dá a definição dêste têrmo: "São falsos aforismos ou desaforos mesmo".

DESBRasilizado adj. - têrmo jocoso que significa: livre do Brasil, sem Brasil: "Enquanto os inquéritos não acabam, o nosso Jusça vai ficando pelas Oropas, gozando o bem-bom de uma vida mansa e desbrasilizada". Correio da Manhã, 11-4-1961.

DESCAPANGUização s.f. - ato e efeito de descapanguizar, isto é, perder as características de capanga: "O "recuperado" Amando da Fonseca sofreu lamentável recaída no seu processo de descapanguização, sábado, quando em companhia de seus leões de favela promoveu uma cena de gangsterismo em Ipanema". Correio da Manhã, 4-4-1961.

DESDOLMANIzar v. - tirar o dólmã: "Alceu, na sua maneira de trazer o fardão, quase me reconciliou com o pomposo uniforme. Sabem todos que as duas peças da imortalidade se compõem de calças e casaca-dólmã. Mas há algum tempo 
que o nosso querido amigo e mestre não cabe dentro daquela disfarçada camisola de fôrça, salvo seja. Então que fêz? Desdolmanizou a casaca, deixando-a aberta sôbre um colete branco. Estava elegantíssimo". Manuel Bandeira, "Na Academia", Jornal do Brasil, 23-4-1961.

DESGERMANIZAÇĀo s.f. - ato e efeito de desgermanizar, isto é, privar de caráter ou elementos germânicos: "o processo da "desgermanização" da música ainda não está terminado", Otto Maria Carpeaux, O Globo, 27-5-1961.

DESGERMANIZADO adj. - privado de caráter ou elementos germânicos: "música desgermanizada", Otto Maria Carpeaux, $O$ Globo, 27-5-1961;

DESINCOMPATIBILIZAÇÃo s.f. - ato e efeito de desincompatibilizar: "o prazo de sua desincompatibilização expirará no dia 2 de maio", Cruzeiro, 6-5-1961.

DESINFLACIONÁRIo adj. - palavra derivada do têrmo "desinflação", comentado em ambos os nossos trabalhos citados: "Nesse sentido, o salário móvel é desinflacionário por excelência, o que é uma vantagem, sobretudo, para o consumidor". $P N$, 24-4-1961.

DESLÉXICo (DISLÉXICO) S.m. - incapacidade de alguém de coordenar palavras em frases: "O menino inverte as letras quando escreve, suas notas de português são baixas, êle lê com dificuldade. Eum desléxico". A Cigarra, a.47, n. ${ }^{\circ} 3$; o prefixo vem provàvelmente do grego: dys.

DESNAZIFICAÇÃo s.f. - ato de desnazificar, isto é, eliminar os restos do nazi-fascismo; vj., p. ex., o artigo de Adolpho Bezerra de Menezes no suplemento literário do Diário de Noticias, 18-4-1961; a palavra apareceu logo depois da Segunda Guerra Mundial.

DESNOMEAR v. - anular uma nomeação: "os 600 candidatos nomeados pelo Sr. Moysés Lupion tiveram de ser desnomeados pelo Sr. Ney Braga", Jornal do Brasil, 12-3-1961.

DESRENUNCIAR v. - cancelar (revogar) a renúncia: "Repetiu o seu ato temperamental quando, lançado já em campanha presidencial, freou de repente e decidiu renunciar para horas depois desrenunciar". Adalgisa Nery, Ultima Hora, 29-4-1961. 
DIETISTA s.m. (f.) - especialista em dieta, dietética: "Peregrino Júnior protestou contra a nomeação de uma dietista argentina para ensinar no Rio Grande do Norte a ciência alimentar". All Right, no Correio da Manhã, 11-3-1961.

DOMINICANIZAÇÃo s.f. - ato e efeito de transformar em domingo um dia comum: "Nunca será tão domingo como aqui, e domingos e domingos da eternidade se concentram em rigorosa dominicanização". Carlos Drummond de Andrade, "O campo visto de passagem", Mundo Ilustrado, n. ${ }^{\circ} 174$.

EJETAR v. - lançar de si: "...o motor-foguete permite, com efeito, acelerar, se êle ejeta os gases para trás, e frear, se os ejeta para a frente", Manchete, n. 471 ; o verbo figura na $10 .^{a}$ ed. de Morais, mas não se encontra no $P D B L P$.

EMBAIXADORAL adj. - têrmo jocoso que significa: relativo ao cargo de embaixador: "Rubem Braga, quando se pergunta como êle se sente como Embaixador, responde: "Muito embaixadoral!", Jornal do Brasil, 16-4-1961.

ENDIVIDAMENTO S.m. - ato de endividar-se; PN 13-3-1961.

ENGENHEIRÁTICo adj. - referente a engenheiro: "a enorme variedade de problemas, desde os físicos, climáticos, até os econômicos, técnico-engenheiráticos", Jornal do Brasil, .... 11-3-1961; barbarismo criado pelo autor do artigo, lembrando "climatérico".

EPISTOLORRÉICO adj. - que escreve cartas ou bilhetes em grande quantidade: "o nosso epistolorréico presidente", Oswaldo Costa, Semanário, 17-24-3-1961; barbarismo formado segundo logorréia, discursorréia, verborréia e segundo os têrmos médicos: diarréia, leucorréia, etc.

ESBURACAMENTO S.m. - ato ou efeito de esburacar: "Um busto ou um monumento de mau gôsto numa praça ou num jardim público, é um atentado à população, como qualquer outro, como o esburacamento das ruas ou o excesso de lixo". Correio da Manhã, 12-3-1961.

espaçodinamismo s.m. - no Correio da Manhãa ...... 11-3-1961, explica-se o têrmo assim: "O espaçodinamismo não é uma palavra vã nem um neologismo, nem uma utopia, mas a expressão de uma aspiração sincera para um equilíbrio, uma 
síntese ordenada porém livre, onde todos os meios do artista criador se desdobrarão para a realização de condições técnicas e estéticas duma ordem social superior na qual o homem poderá se desenvolver, se expandir e alcançar a alegria de viver". A formação do composto não é própria do português e lembra a formação, p.ex.,no alemão.

ESPAÇONAVE S.f. - nave espacial, nave cósmica: "O lançamento, pelos russos, de sua quarta espaçonave com um cão a bordo", Diário da Noite, 10-3-1961; formação analógica a aeronave, belonave.

ESQUERDIZANTE adj. - com tendências para a esquerda (politicamente): "uma política exterior esquerdizante", Jornal do Brasil, 15-3-1961.

EXTRATERRESTRE adj. - fora da Terra: "espaço extraterrestre", Diário da Noite, 13-3-1961; já existiu a palavra "extraterreno".

eSTRELato S.m. - grau ou título de "estrêla" de cinema: "alcançar definitivamente o estrelato", Mundo Ilustrado, n. ${ }^{\circ}$ 175.

FILME-JORNAL S.m. - cine-jornal, filme de atualidades: "Importância dos filmes-jornais", Leo Gilson Ribeiro, Jornal do Brasil, 11-3-1961.

FILMOGRAFIA s.f. - têrmo calcado em "bibliografia" e que significa: relação das obras cinematográficas de um produtor ou diretor de cinema: "Fui assistir ao filme de Hitchcock, "Psicose". Não chega a ser um filme sequer razoável, devendo se colocar como um dos mais fracos na filmografia do famoso diretor". Diário de Notícias, 7-3-1961.

FLAGRAR v. - apanhar, pegar em flagrante: "O leitor também flagra...", Correio da Manhã, 1-3-1961.

Fotosemana s.f. - fotografia da semana; Correio da Manhä, 11-3-1961.

GABILHETE S.M. - trocadilho pilhérico criado por cruzamento de gabinete e bilhete para designar a Casa Civil ou Militar do Presidente Jânio Quadros, de onde se expedem os bilhetinhos: "A produção em massa de bilhetinhos janistas já fêz que Brasília apelidasse sua Casa Civil e Militar de "Ga- 
bilhete Civil e Gabilhete Militar", Correio da Manhã , ..... 10-3-1961.

GALINHADA s.f. - pratos de galinha constantemente repetidos: "Mais de 15 galinhas já haviam sido sacrificadas nos festins noturnos da cadeia de Joinville, quando um prêso, farto da galinhada, bateu com a língua nos dentes, acabando com a mamata". Visão, 10-3-1961; a terminação -ada indica grande quantidade.

GRANFA s.m. - grã-fino; forma popular de giria que lembra o tipo: portuga (forma regressiva): "O sr. Emílio Carlos é todo granfa...", Stanislaw Ponte Preta, Diário da Noite, 5-4-1961; cf. analfa (=analfabeto), usado pelo mesmo autor, Diário da Noite, 19-4-1961; a palavra granfa figura em A Giria Brasileira, de Antenor Nascentes.

GUANDUNIZAÇÃo s.f. - ato de guandunizar, quer dizer, punir devido ao mau funcionamento de Guandu, como aconteceu, por decisão do Governador Lacerda, com o Secretário da Viação de então, Arlindo Laviola, e alguns engenheiros: "a guandunização de outras figuras do "staff" de Lacerda", Correio da Manhã, 10-3-1961; palavra efêmera.

HELIOPIROMETRIA S.f. - têrmo técnico que significa: medição do calor radiante do Sol, Jornal do Commercio, ...... 22-4-1961.

HIPoNeCRópole S.f. - cemitério de cavalos; "Domingo, na Gávea, dizia-se em tom de piada, que o responsável pela lei marota contra o turfe fôra o governador Carlos Lacerda. Assistindo à corrida noturna em sua homenagem, dias antes do seu tête-a-tête com JQ, em Brasília, Lacerda descobrira que o hipódromo era o local ideal para o novo cemitério que o Rio reclama. E não teve dúvidas: incluiu nas reivindicações da Guanabara a hiponecrópole". Correio da Manhã, .. 16-5-1961; têrmo jocoso.

INDESMENTível adj. - o que não se pode desmentir: "numa análise lógica indesmentível”, Jornal do Brasil, 11-3-1961.

INTERSIDERAL adj. - entre os astros, cósmico: “Quando subiu o "Sputinik I", em vários países se formaram filas de candidatos à primeira viagem intersideral, em astronave ainda não construída de navegação ainda inexistente". Carlos 
Drummond de Andrade, "Cosmonauta", Correio da Manhã, 15-4-1961; neologismo bem formado.

ITAMARATIANo adj. - referente ao Itamarati: "um pouco fora do enquadramento itamaratiano", Joel Silveira, Diário de Noticias, 16-4-1961.

IIPÃo s.m. - tipo grande de jipe: “cada jipão do Exército", Carlos Drummond de Andrade, Correio da Manhã ,.... 17-3-1961; muito comum, p.ex., no Nordeste.

JUMENTALIDADE s.f. - mentalidade de jumento (no sentido figurado): "intérprete fiel da alta jumentalidade da burguesia desarvorada", Barão de Itararé, Última Hora, ...... 10-3-1961; palavra pilhérica e efêmera criada por cruzamen. to de "jumento" e "mentalidade";

LIBERALIZAÇÃo s.f. - ato ou efeito de liberalizar: "liberalização do comércio", Jornal do Brasil, 5-3-1961; "liberalização imediata dos 500 milhões de dólares", ibidem, 15-3-1961.

IIGHTIANo adj. - referente à companhia Light: "os notáveis conselhos do lightiano Corção", Adalgisa Nery, última Hora, 15-3-1961.

MARGINALIZAÇÃo s.f. - ato de tornar marginal, isto é, colocar na margem (aqui: das preocupações econômicas do Estado); têrmo empregado pelo Governador Brizzola, referindo-se a "marginalização do Rio Grande do Sul", Jornal do Commercio (Pernambuco), 14-5-1961.

MULTIMODELAdo adj. - modelado de muitas maneiras: "a efígie de Jimmy Dean multimodelada nos ateliers da Califórnia", Jornal do Brasil, 4-3-1961.

MUSICALIZAÇão s.f. - "Despertar e desenvolver as qualidades musicais inatas, buscando o desenvolvimento do senso rítmico e o aprimoramento da audição: ensinar a apreciar melhor a música, dando noções gerais dos seus principais estilos e formas", Correio da Manhã, 5-3-1961; usa-se, também no sentido de: "musicalização de um tema qualquer".

NEGATIVIDADE $\mathrm{s.f}$. - não significa sòmente "estado de um corpo que revela eletricidade negativa (fís.)" (PDBLP), mas também "negação", "negativismo", "qualidade de negativo", sendo uma das muitas palavras eruditas em -tividade: "Ex- 
pressão do mundo interiorizado a lírica é também comunicada como um tempo em pura negatividade". Jornal do Brasil, 25-2-1961.

NEGocismo s.m. - ação ou procedência de negocista ou negocistas, uma série de negocistas: "Réu de negocismo", Correio da Manhã, 19-3-1961.

NORDESTINIZAR V. - tornar atrasado como o Nordeste do Brasil: "português nordestinizado pelo sol da Borborema", Correio da Manhã, 12-3-1961.

Novacapiano adj. - de Nova Cap, brasiliense; Correio da Manhã, 19-4-1961.

NUTRóLoGo s.m. - significa "nutricionista", mas há diferença semântica entre êstes dois têrmos; o nutrólogo é um especialista teórico, enquanto que o nutricionista é um prático que ensina a preparar o alimento, que aconselha a dieta, etc.: "Peregrino Júnior/.../está certo, certíssimo, quando critica a nomeação da nutróloga argentina para ir lecionar no seu Estado...", All Right, Correio da Manhã, 11-3-1961.

ONDA-Novista s.m. - aquêle que pertence à onda (=bossa) nova, à "Nouvelle vague", vj. Stanislaw Ponte Preta, Diário da Noite, 15-4-1961; criação individual do jornalista.

PARABENIZAR v. - felicitar, dar os parabéns: "Foram parabenizar Ariane na inesquecível noite da sua apresentação à sociedade", Jornal do Commercio (Pernambuco), 10-5-1961; barbarismo já existente algum tempo na língua.

Paraíba s.f. - mulher lésbica, que atrai as jovens para as suas orgias (expressão da gíria); também pode significar: mulher agressiva, valente; vj. Diário da Noite, 6-3-1961; a palavra é talvez uma alusão a um baião muito popular no comêço da década de 50, cantando o Estado da Paraíba, de onde é originário o autor, Luiz Gonzaga: "Paraíba masculina, mulher macho, sim senhor".

PARQUEAMENTO s.m. - estacionamento em parques de aterrissagem: " 53 convidados compareceram em seu avióes particulares, provocando grandes confusões no parqueamento da frota aérea". Correio da Manhã, 5-4-1961; imitação do inglês. 
PAULISTANISMO s.m. - palavra alusiva aos habitantes de São Paulo, criada segundo "regionalismo"; aparece em Manchete, n. ${ }^{\circ}$ 471, num artigo sôbre as Novelas Paulistanas, de Antônio de Alcântara Machado.

PIJANIO s.m. - peregrinismo pilhérico explicado no seguinte trecho do Diário da Noite, 12-4-1961: "O novo uniforme hindu que o presidente da República mandou adotar oficialmente pelo funcionalismo público, está sendo chamado de "pijanio" com a explicação de que se trata de um híbrido de farda de guarda-civil com pijama".

PINOT (т) INA s.f. - segundo a Tribuna de Imprensa, ... 3-5-1961, é uma gratificação que era paga a funcionários do Departamento Nacional de Endemias Rurais "por serviços que nunca foram prestados", durante a gestão do Ministro Mário Pinotti.

PRÉ-CANDIDATo S.m. - candidato à candidatura oficial: "Em declaração distribuída à Imprensa e que será lida no Senado, o parlamentar que foi pré-candidato democrata à presidência dos Estados Unidos, antes de ser derrotado por John Kennedy, afirmou..." Correxio da Manhã, 10-5-1961.

PRÉ-CaRnavalesco s.m. - período um pouco antes do carnaval: "a tradição do pré-carnavalesco", Mundo Ilustrado, 18-2-1961; palavra já muito tempo conhecida.

PRÉ-DITADURA S.f. - época que precede a instauração de uma ditadura, fase pré-ditatorial; vj. Diário Carioca, ..... 11-3-1961.

PRÉ-MAMÁ s.f. - mulher grávida, pouco tempo antes do parto; a palavra, de criação individual, aparece numa crônica de Henrique Pongetti, Manchete, n. ${ }^{\circ} 470$.

PUBLI-POEMA s.m. - poema com fins publicitários; cf. Manchete, n. ${ }^{\circ}$ 474, onde aparece também a expressāo: publi-reportagem.

PULA-PUla s.m. - ato de pular; Cruzeiro, 25-2-1961.

REBOLATIvo adj. - rebolado: "lides artísticas-rebolativas teatrais", Stanislaw Ponte Preta, Diário da Noite, 9-3-1961; criação efêmera. 
REPETECo S.m. - repetição (pejorativamente): "fantasia de luxo (não vale repeteco de fantasia do longínquo carnaval de 61)", Diário da Noite, 18-2-1961; cf., também: Correio da Manhã, 10-3-1961.

REPRESENTATIVIDADE S.f. - qualidade de ser representativo: "as instituições, na sua máxima representatividade", o Presidente Jânio Quadros, citado por Última Hora, 16-3-1961.

SATELITIZaÇÃo s.f. - ato de satelitizar: "as acelerações... devem ter a velocidade de "satelitização" $(8 \mathrm{~km}$ /segundo)"; "a "satelitização" de cem toneladas numa órbita", Manchete, n. 0471.

SATELITIZAR v. - lançar um objeto ao espaço com uma velocidade prèviamente calculada que lhe permita entrar em órbita: "os soviéticos "satelitizam" correntemente cargas úteis de cinco toneladas"; "para essa operação é preciso "satelitizar", mais ou menos, cem toneladas", Manchete, n. ${ }^{\circ} 471$.

SELETIVIDAdE S.f. - processo de seleção, qualidade de seletivo: "Necessàriamente terá de haver uma seletividade no encaminhamento dos recursos disponiveis de financiamento", Correio da Manhä, 11-3-1961.

SERIADO s.m. - filme em série: "Primeiro Seriado Brasileiro para Tr", Stanislaw Ponte Preta, Diário da Noite, ... 13--5-1961; adjetivo substantivado. O adjetivo seriado existe já algum tempo; p.ex.: "Filme seriado", título de um conto de Décio Alvarenga Mafra na Singra, n.o 474.

SUBDESENVOLVIMENTISTA adj. - relativo ao subdesenvolvimentismo; palavra criada segundo o desenvolvimentismo; $p$. ex., Diário da Noite, 14-3-1961: "literatura subdesenvolvimentista" (=que trata dos assuntos afro-asiáticos).

SUBINDEPENDÊNCIA s.f. - independência aparente; de caráter semelhante são as duas outras palavras empregadas no nosso exemplo: subsoberania (=soberania não verdadeira), sub-sub-liberdade (falta absoluta da liberdade) : "as causas da nossa subindependência política, da nossa subsoberania, da nossa sub-sub-liberdade econômica", Adalgisa Nery, vitima Hora, 24-2-1961.

SUPERCAPITALISTA adj. - que tem características bem 
acentuadas de capitalista, capitalista altamente desenvolvido, plutocrata; vj. Oswaldo Costa, Semanário, 17-24--3-1961.

SUPER-PRESIDENTE S.m. - "Tornou-se um super-presidente, tudo monopolizando, a todos os assuntos dedicando a sua atenção, desde questōes de somenos importância ate problemas da maior transcendência", $P N$, 13-3-1961.

TRAVESTIDO S.m. - travesti: "O travestido elegante não pula carnaval". Manchete, n. ${ }^{463}$; adaptação do francês "travesti".

VENTRLOQUISMO s.m. - característica de ventríloquo: "ela nada tem de ventriloquismo", Diário da Noite, 13-3-1961.

zONEAMENTo s.m. - ato ou efeito de zonear, isto é, dividir em zonas, ou, em alguns casos, localizar, dentro da cidade, agrupamentos de casas, fábricas, locais de trabalho ou diversão, parques, etc.: "Os primeiros passos para a atualização do zoneamento do País, para efeito de níveis de salário mínimo, deverão ser dados depois de amanhã...", Jornal do Brasil, 28-2-1961; a palavra tem aproximadamente 15 anos e lembra: loteamento.

Para terminar o artigo, queremos completar algumas informações contidas nos nossos dois citados estuduos.

1) A relação dos estudos e artigos que foram publicados no Brasil, ocupando-se do problema da linguagem jornalística, precisamos acrescentar um artigo de V. Coaracy, "Decadência da linguagem", publicado no Correio da Manhã, 20-4-1961. No artigo o autor se queixa da decadência da linguagem das classes "que se supõem cultas, dotadas necessàriamente de determinado nivel de instrução e de um mínimo de inteligência e lucidez". "Não estou me referindo só a lapsos gramaticais, erros de regência, de colocação e até de concordância, do que há exemplos. Refiro-me muito especialmente à clareza da linguagem, à construção da frase, à expressão precisa e sem ambigüidades do pensamento que se pretende traduzir. Neste terreno observa-se verdadeiro descalabro". . . "Para ilustrar de modo exemplar o que estou dizendo não é preciso ir longe nem pesquisar muito. Basta ouvir, diga-se, um programa de rádio ou de televisão. Basta ler o noticiário de bom número de nossos jornais. Colher-se-ão às braçadas amostras do vilipêndio a que é submetida esta po- 
bre e maltratada língua portuguêsa que falamos. Os efeitos desastrados se multiplicam, porque é ouvindo o rádio e lendo os jornais que o povo aprende a falar e se exprimir, aumentando o seu vocabulário e adquirindo modos de dizer".

2) Como já dissemos nos referidos trabalhos, às vêzes os próprios jornalistas ou escritores que escrevem para jornal, esclarecem o significado de palavras ou comentam fatos de linguagem. De mais um exemplo pode servir Pedro Bloch na sua "A moda das palavras", Jóia, n. 0 78:

"O nosso grande Tristão de Ataíde escreveu recentemente um brilhante artigo em que focalizava as palavras que iam mudando de sentido, ganhando novas intenções, adquirindo novos valores. Antigamente foguete fazia lembrar o quê? Uma festa de São João, fogueira, vestidos de chita, batata doce assada... quanta coisa mais! Hoje foguete lembra Cabo Canaveral.

Vocês já repararam como andou em moda a palavra conjuntura?

Foi um tal de conjunturar que não acabava mais. Quem não falasse na conjuntura política, na conjuntura econômica. . estava frito.

O Presidente Iânio criou a moda do "no que tange". Agora todo mundo vive tangendo em vez de se referir a... No que tange $a$ isso, no que tange àquilo...

Curioso é como a gíria também tem suas fases. As vêzes vai e volta. As vêzes some de vez. Agora estamos na fase do "entrou pelo cano", "crocodilou", "matusca" (doido) e assim por diante.

Decididamente as palavras, muitas vêzes, também entram pelo cano... direto".

Na revista Quatro Rodas, abril de 1961, encontramos explicações da palavra Kart: "Em tôdas as partes do mundo, onde se vai implantando, o Kart vai criando derivações em tôrno do seu nome; mas, geralmente, respeitam-se os sucedâneos inglêses, como "Karting" e outros. Aqui no Brasil, sua inicial provocou dificuldades, pois é uma letra exótica, estranha à grafia portuguêsa. Mas tem sido respeitada e a pista 
de corridas vai chamar-se Kartódromo, os corredores Kartistas e o esporte tende para Kartismo. Nada, contudo, está no dicionário". E mais adiante lemos: "Kart, substantivo masculino. Carro leve e potente, veloz e barato, baixinho e barulhento, surgido há 4 anos nos Estados Unidos onde, como esporte, ainda é um grande sucesso; considerado jardim de infância para automobilistas; começou como aparador de grama e hoje é fabricado por grandes indústrias; ainda sem futuro definido no Brasil".

Da palavra cart está derivado cartesiano numa nova acepção: "Em Brasília, quem guia um "kart" é conhecido como cartesiano". (Correio da Manhã, 19-4-1961).

3) Nos nossos trabalhos anteriores citamos também casos de aportuguesamento de palavras estrangeiras (eslaque, esputinique, etc.). Podemos, hoje, citar mais três exemplos: "Não se esqueça de nosso eslogan". Eneida no Diário de Notícias, 16-4-1961 (=slogan). - "A senhora... não é candidata a misse..." Stanislaw Ponte Preta, Diário da Noite, ... 14-4-1961 (lembra o aportuguesamento do tipo: chef $>$ chefe). Assim grafada (por engano?) encontramos esta palavra já em Afrânio Peixoto, A esfinge, ed. 1944, p. $14-\mathrm{E}$ o terceiro exemplo: "grande toalete para uma grande "soirée", Jóia, n.o 78. Da gíria - ou para usarmos a feliz expressão de Antenor Nascentes: da "gíria elegante" ( $A$ Manhã, 6-2-1949, isto é a gíria da "alta sociedade") - vem a expressão ocloque: "brincadeira tem ocloque", Cruzeiro, 29-4-1961, isto, é: "tem hora, tem seu tempo".

A influência do inglês, da qual falamos nos nossos artigos anteriores, é comentada também numa nota, publicada na revista $P N, 24-4-1961$, de autoria de A. P. Carvalho:

"Entre as 13 palavras que figuram na tabuleta de um bar a abrir-se na Cinelândia, 9 são em inglês. O nome do esta. belecimento é inglês - "Bar-Kid's" e os nomes da maior parte dos quitutes que servirá ao respeitável público carioca (?) são igualmente na língua de Elvis Presley. Aí vão êles: hamburgers, cheesburges, ham \& eggs, tuna, hot-dogs, chicken-salad. Na nossa pobre língua tem apenas êstes vocábulos rotineiros: sorvetes, sucos, e, breve inauguração. - Como se arranjará o freguês para ser servido?... De certo terá que 
levar um dicionário. Quanto aos preços, segundo o prof. Bergamini, deverão ser em dólares, pois, com tanto espavento norte-americano, cobrar em cruzeiros seria ridículo. Confere".

O predomínio da influência do inglês, em prejuízo do francês, vê-se, p.ex., na suplantação de charmant(e) por charming: "Sempre bonita e "charming", a conhecida e querida Violeta Botelho...", Jornal do Commercio (Pernambuco), 10-5-1961.

4) Nos artigos anteriores falamos também da penetração das expressões e locuções características do esporte em outras secções do jornal. Aqui está mais um exemplo: "Soubemos que Elisa Cunha de Castro está na pista para receber uma aliança de noivado". Jornal do Commercio (Pernambuco), 10-5-1961.

5) Os novos materiais nos permitem completar as definições ou explicações de alguns dos novos têrmos, anotados nos nossos trabalhos publicados na $R B F$. Quanto ao

ALARMISMo s.m. que definimos como "uma série de alarmes, uma onda de boatos alarmantes", podemos citar mais uma abonação em que a palavra aparece no plural: "... evitar quaisquer alarmismos da parte do povo". Fatos e Fotos, n. ${ }^{\circ} 6$.

A palavra aNTICARIoca s.m., definida por nós como "pessoa contrária aos verdadeiros interêsses do Rio de Janeiro", aparece outra vez na Ultima Hora, 15-2-1961, mas isto não lhe tira o caráter de palavra sem muita vida.

A palavra Biquinı começou a usar-se, na gíria carioca, num sentido figurado: "Não foi feliz o sr. Jânio Quadros, na tentativa de emendar a mão com respeito ao caso do horário de serviço do funcionalismo federal. Se a medida inicial, da divisāo em dois turnos, que recebeu imediatamente a denominação popular de horário "biquini", suscitou dificuldades materiais ao funcionalismo, contra as quais se levantou, muito justamente, a classe, a correção das situações injustas foi feita de tal forma que oferece ao problema uma solução impraticável". Diário de Notícias, 19-3-1961. Da palavra biquini, no próprio sentido que a expressão tem, foi derivado o advérbio biquinicamente: "biquìnicamente sedutora", Correio da Manhã, 14-5-1961. 
Do verbo onomatopéico de cunho jocoso, citado no segundo dos nossos estudos anteriores: blábláblar, foi derivado pelo criador do têrmo, Stanislaw Ponte Preta, o substantivo blablabá: "os invejosos iniciaram o blablablá", Diário da Noite, 15-4-1961.

Aos compostos com -brás acrescentemos: Pelebrás "Carlos S. Pereira, de Santos, aplaude a idéia do leitor Alexandre Cardoso, do Rio, de fundar-se a Pelebrás, destinada a garantir a permanência de Pelé no Brasil. - E entreguismo deixar Pelé ir para a Europa - diz êle”. Manchete, n.o 470.

Quanto a um outro têrmo, registrado em "Mais algumas notas sôbre a linguagem da imprensa brasileira contemporânea": cineclubismo, trancrevamos aqui uma explicação do têrmo e do fenômeno, a qual foi publicada nos Novos Rumos, 21-27-4-1961: "O cineclube é uma entidade autônoma, registrada ùnicamente para fins culturais, já estando organizado em federações regionais, nacionais e internacionais. Para melhor clareza de seus objetivos, daremos a seguir a definição adotada pela Federação Internacional de Cineclubes, com sede em Paris: 'Será considerada como cineclube tôda a entidade não comercial que tenha por fins exclusivos o que segue: contribuir para o progresso da cultura dos estudos históricos e da técnica cinematográfica; ajudar o desenvolvimento do intercâmbio cultural do cinema entre os povos; e, por fim, estimular a difusão do filme experimental'."

Ao lado de granfinagem (vj. "Mais algumas notas...") encontramos o têrmo equivalente granfinada (José Condé, Um ramo para Luiza, 40).

Sãopaulizar ("Para o estudo...", 2.5) aparece na forma sampaulizar em Manchete, 15-4-1961. 